\title{
A further investigation of an observing response analysis of fixed-ratio discrimination
}

\author{
STEPHEN B. KENDALL ${ }^{1}$ \\ UNIVERSITY OF ALABAMA
}

Observing responses in three pairs of mixed fixed-ratio schedules were studied. In each pair, the duration of the stimulus produced by the observing response was systematically shortened. It was found that observing responses could be maintained when the FR schedules were FR40 and FR50 at all stimulus durations except 1 sec. This is in contrast to a previous study where observing responses extinguished at a mixed FR30 FR50 schedule.

In a previous study (Kendall, 1965b), observing responses were studied in three mixed schedules, FR10/FR50, FR20/FR50 and FR30/FR50. It was assumed that when discrimination between the two FRs broke down, observing responses would cease. Observing response output was maintained when the lower FR was FR10 or FR20 but not when it was FR30.

In that experiment an observing response produced a red light during the lower FR and a blue light during the higher FR. The stumulus produced by the observing response had a maximum duration of $5 \mathrm{sec}$. It was also terminated by reinforcement if the subject emitted an FR in less than 5 sec. This stimulus duration was entirely arbitrary. Ordinarily, a pigeon will emit an FR10 in less than 5 sec and may emit an FR20 in that length of time.

The present experiment is a replication of the previous study using different stimulus durations. An attempt was made to determine if observing responses could be maintained when the lower of the pair of FRs was FR30, or higher if different training procedures were used. These different training procedures consisted of systematically shortening the duration of the stimulus produced by the observing response.

Mothod

The Ss were two naive Silver-King pigeons (SK-65 and SK-73). They were run at $80 \%$ of their free-feeding weight throughout the study.

The experimental apparatus was a two-key pigeon chamber housed in a larger sound attenuating chamber. All programming was accomplishedby electromechanical devices and responses were recorded on a cumulative recorder and counters.

When the birds had been key trained by successive approximation, they were exposed to progressively larger fixed-ratio (FR) schedules until FR30 was reached. In an FR30 schedule, 30 pecks at the response key produces reinforcement. In this case, the reinforcer was $3.5 \mathrm{sec}$ access to mixed grain. Following training on FR30 they were exposed to a mixed FR20/FR50 schedule. In the mixed schedule, FR20 and FR50 appear successively in an unsystematic order with no stimulus change to indicate to the bird which of the FRs is in effect. Following training on the mixed schedule, the birds were exposed to a multiple schedule of FR20/FR50. The multiple schedule was like the mixed schedule in every respect except that a red light illuminated the response key during FR20 and a blue light during FR50.

Following the above initial training, the birds were trained to make observing responses. They were returned to the mixed schedule during observing response training. They were trained to peck the observing key by being given a few initial grain reinforcements for doing so. When grain reinforcement for pecking the observing key had been discontinued, the only contingencies for pecking the observing key became the illumination of the food key with the color appropriate to the current FR.

Three pairs of FR values were used in the experiment FR20/FR50, FR30/FR50 and FR40/FR50. These pairs of schedules were introduced in this order. Within each mixed FR schedule the stimulus duration was systematically shortened. Initially, the length of the stimulus was the duration of the FR schedule. Thus, when an observing response was emitted, the stimulus lasted until the next reinforcement was delivered. Other durations were 15 , 5 and $1 \mathrm{sec}$. The Ss were exposed to the stimulus durations in that order within a given mixed FR schedule. The red light always remained correlated with the shorter FR, and the blue light with the FR50.

The birds were run under each condition of the experiment until stable performance had been achieved. Results

The results are presented in terms of an "observing ratio" in Fig. 1. The use of the observing ratio has been discussed previously (Kendall \& Gibson, 1965). It is the number of stimuli obtained, divided by the number of reinforcements obtained. Thus, if the $S$ makes only one observing response in each schedule component, the ratio will be 1.00 . This was the upper limit in the case where the stimulus lasted for the duration of a given schedule component.

One consideration should be kept in mind concerning the results. If a stimulus was present, it terminated at reinforcement. Thus, although the maximum stimulus duration might have been $15 \mathrm{sec}$, it could have been shorter if the $\mathrm{S}$ completed the schedule in less than 15 sec.

There are certain similarities and differences between the two Ss. For each S, the shorter stimulus duration curves lie above the longer curves indicating an increase in observing response output as the duration of the stimulus is decreased. The one exception to this is that for both subjects, the observing ratio at 


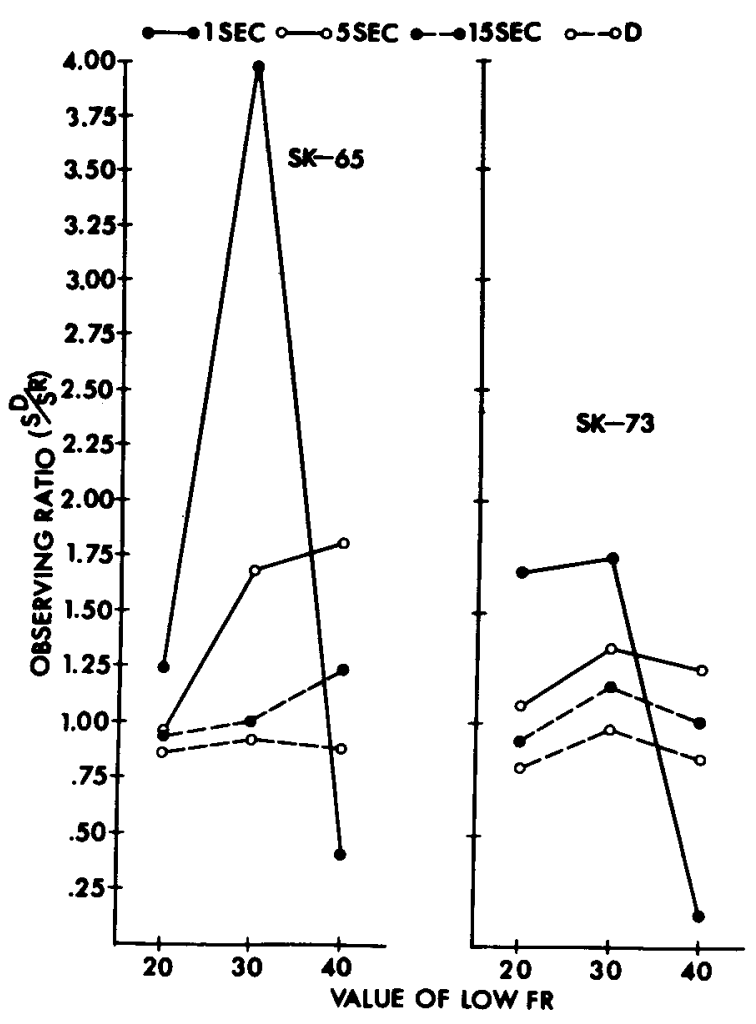

Fig. 1. Observing ratios for each of the $S s$ at each value of the mixed FR FR schedule. The higher FR was always 50. The four curves for each $S$ represent the different stimulus durations.

FR40/FR50 is very low when the stimulus duration is 1 sec.

The major dissimilarity, aside from differences in the absolute magnitude of observing behavior at certain points, is the change that occurs when going from FR30/FR50 to FR40/FR50. There is an increase in observing response output for SK-65 at the 5 and $15 \mathrm{sec}$ stimulus durations. For $\mathrm{SK}-73$ there is a decrease. Discussion

Despite some unexplained differences between the two
Ss, the results indicate that observing behavior can be maintained at FR30/FR50 food schedules at all stimulus durations. Observing behavior was also maintained at FR40/FR50 at three of the stimulus durations. The only duration which produced a low observing response output was the 1 sec condition. This is in contrast to the previous study (Kendall, 1965b), where observing behavior was not maintained at all at FR30/FR50.

The inajor difference between the two studies was the training procedure employed. In the original study a 5 sec stimulus duration was used in all phases of the experiment. It would appear that the progressive reduction of the duration of the stimuli at each pair of FR schedules is responsible for the present results.

A previous experiment demonstrated that observing responses tend to occur following reinforcement, before responding on the food keys begins (Kendall, 1965a). Assuming this to be the case in this study, the stimuli tend to become more remote from reinforcement as the stimulus duration is shortened. If the stimuli have terminated prior to reinforcement, they could be referred to as "differential trace stimuli" since reinforcement will always be received in the presence of the mixed stimulus.

The present results suggest that differential trace stimuli can be most effectively employed if the duration of the stimuli is progressively shortened.

The present results are also more in line with those of Rilling \& McDiarmid (1965) who, by a completely different method, demonstrated that pigeons can discriminate between FR40 and FR50 schedules.

\section{References}

KENDALL, S. B. The distribution of observing responses in a mixed FI-FR schedule. J. exp. Anal Behav., 1965a, 8, 305-312.

KENDALL, S. B. An observing response analysis of fixed ratio discrimination. Psychon. Sci, 1965b, 3, 281-282.

TILLING, M., \& McDIARMID, C. Signal detection in fixed-ratio schedules. Science, 1965, 148, 526-527.

Note

1. Now at the University of Western Ontario, London, Ontario, Canada 